\title{
Analysis on the Microstructure and Mechanical Properties of Welding Joint of Low Alloy Structural Steel Plate by Narrow Gap
}

\section{MAG}

\author{
Bingjun Chen \\ School of Mechanical and Power Engineering \\ Wuhan University \\ Wuhan, China \\ E-mail:cbj@whu.edu.cn
}

\section{Wenkai Xiao}

School of Mechanical and Power Engineering

Wuhan University

Wuhan, China

E-mail:xiaowenkai@whu.edu.cn

\author{
Li Zhu \\ School of Mechanical and Power Engineering \\ Wuhan University \\ Wuhan, China \\ E-mail: $278069641 @ q q . c o m$ \\ Fuju Zhang \\ School of Mechanical and Power Engineering \\ Wuhan University \\ Wuhan, China
}

\begin{abstract}
The narrow gap automatic MAG welding equipment in this article is a narrow gap gas metal arc automatic welding system developed by Wuhan University, which has remarkable advantages of low heat input and high efficiency. The low heat input reduces the tendency of grain coarsening and other bad non-equilibrium structures in the weld microstructure, improving the mechanical properties of welding joints. Selecting the welding of low carbon low alloy structural steel-Q345B as the research object, this paper systematically analyses the microstructure and mechanical properties of Q345B welding joint by narrow gap automatic MAG welding process, it turns out that the weld joint obtains good mechanical properties in this way.
\end{abstract}

Keywords-Q345B steel;the narow gap automatic welding; metal; microstructure; property.

\section{INTRODUCTION}

Q345B steel is a low carbon low alloy structural steel (Wc $<0.2 \%$ ), which has favorable integrated mechanical properties, good low-temperature performance as well as excellent plasticity and weld ability. It's often used in low or medium pressure vessel, oil tank, vehicles, cranes, mining machinery, power stations, bridges, machinery parts, building structure and the general metal structure at hot rolled or normalizing state, above -40 degrees centigrade. At present, MAG welding(Metal Active-Gas welding) is widely used in the Q345 steel welding field, When the shielding gas mainly consists of $\mathrm{Ar}$ and a small amount of active gases such as $\mathrm{CO}_{2}, \mathrm{O}_{2}, \mathrm{CO}_{2}+\mathrm{O}_{2}$, etc, this welding procedure is called metal active-gas welding, namely MAG welding [1-3] . MAG welding has the characteristics of the argon arc welding, such as stable arc, less spatter and easy to get the spray transfer. At the same time, it has certain oxidability, which can overcome these shortcomings of pure argon arc welding, such as overlarge surface tension, thick liquid metal, spot drift, etc, in this way, better weld form ability is obtained. Due to the addition of some $\mathrm{CO}_{2}$ to argon gas, the oxidizing reaction in the arc is intensified, giving off more heat and increasing the weld penetration depth, therefore, the filler metal melting coefficient is enhanced [4-5].In this paper, we mainly study the microstructure and mechanical properties of the widely used low alloy steel Q345B welding joints by narrow gap automatic welding process [6].

\section{WELDING PROCEDURE}

These weldments are provided by some engineering machinery plant and the base metal is Q345B steel, whose chemical composition is shown in TABLE I.

TABLE I. THE CHEMICAL COMPOSITION OF Q345B STEEL

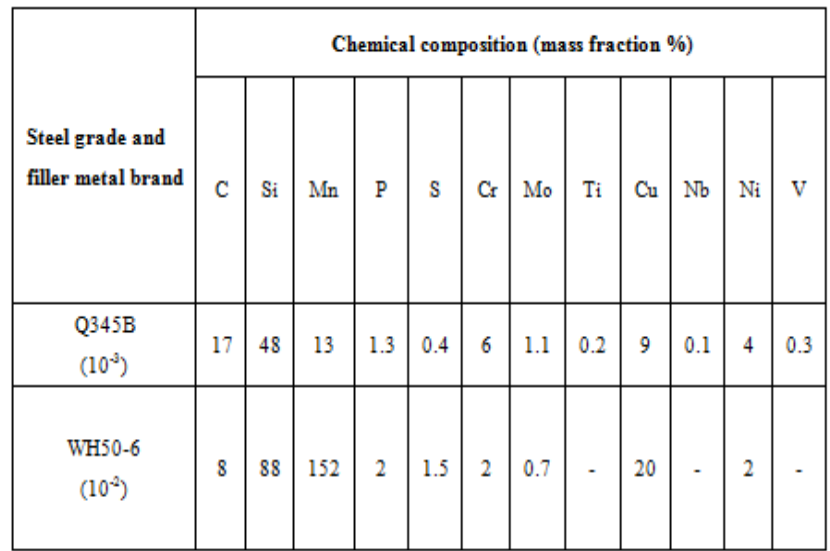

Filler metal: iron anchor WH50-6, $1.2 \mathrm{~mm}$ in diameter. 
Shielding gas: Ar+CO2 $(80 \%+20 \%)$ gas mixture. The weldment butt joint is shown as Fig .1.

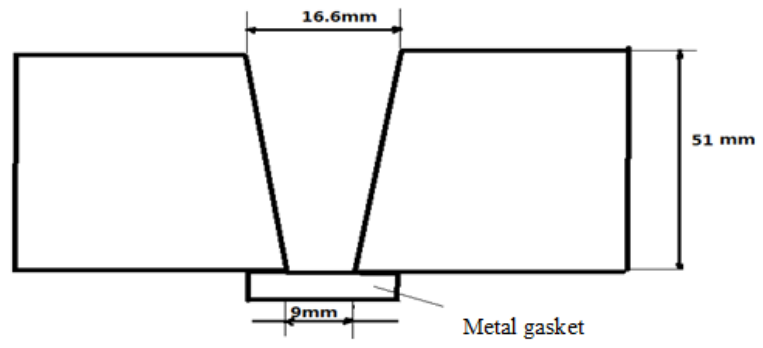

Figure 1. The narrow gap automatic MAG welding butt joint of 50 mm thick Q345B steel plate

The average welding heat input of the narrow gap automatic MAG welding in this paper is shown in TABLE II.

TABLE II. THE AVERAGE NARROW GAP AUTOMATIC MAG WELDING HEAT INPUT

\begin{tabular}{|c|c|c|c|}
\hline $\begin{array}{c}\text { Current/set } \\
\text { voltage } \\
\text { (A/V) }\end{array}$ & $\begin{array}{c}\text { Actual } \\
\text { current/voltage } \\
(\mathbf{A} / \mathbf{V})\end{array}$ & $\begin{array}{c}\text { Welding } \\
\text { speed(mm/s) }\end{array}$ & $\begin{array}{c}\text { Linear } \\
\text { energy(kJ/cm) }\end{array}$ \\
\hline $200 / 23.6$ & $195-205 / 26-26.3$ & 4.5 & 10.3 \\
\hline
\end{tabular}

Filler metal side bending and multi-layer welding process are used, that is, welding from the weld bottom to the top and repeating the welding process several times after the previous weld layer's solidification.The multi-layer welding process is shown as Fig .2.

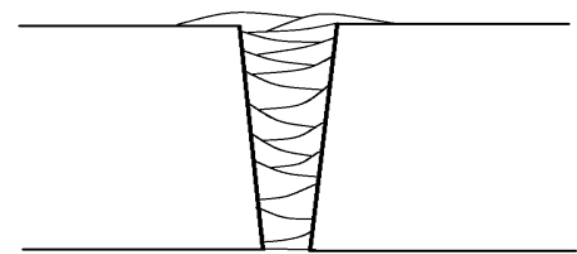

Figure 2. Multi-layer welding process

\section{WELD MICROSTRUCTURE}

A. The comparison of grain size between different welding joint microstructures

Normalized Q345B is used as base metal (BM) in this paper, which consists of equiaxed ferrite and pearlite. There are incompletely normalized zone (INZ), completely normalized zone (CNZ) and overheated zone in the HAZ. Because of the multi-layer welding process, after solidification, the last layer will be heated again by the next layer's molten pool, resulting a secondary heat treatment [7]. Hence, there are secondary incompletely normalized zone (SINZ), secondary completely normalized zone (SCNZ) as well as columnar zone which is not affected by the secondary heat.The microstructure comparison chart of the above-mentioned six zones is shown in Fig .3.

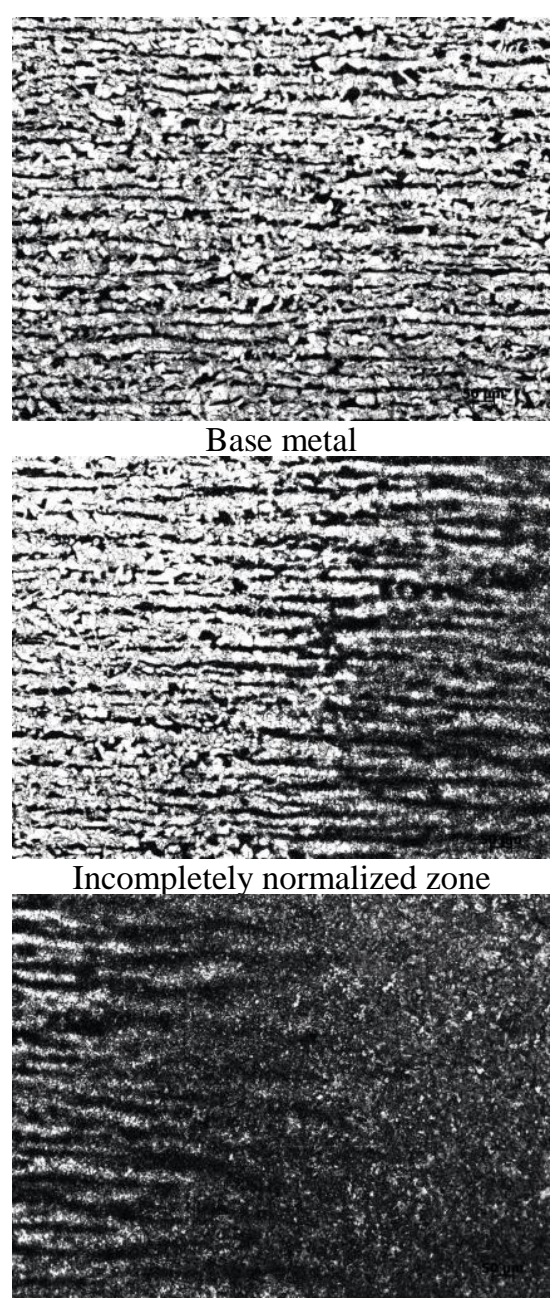

Completely normalized zone

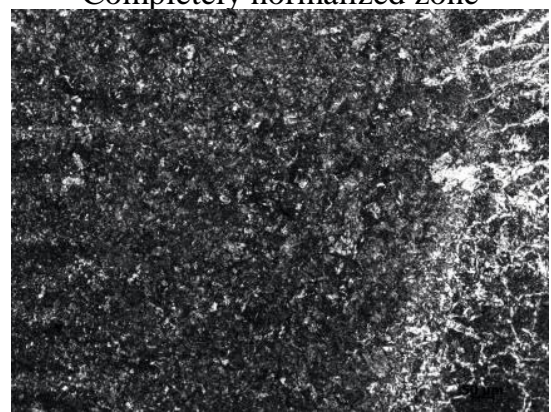

Overheated zone

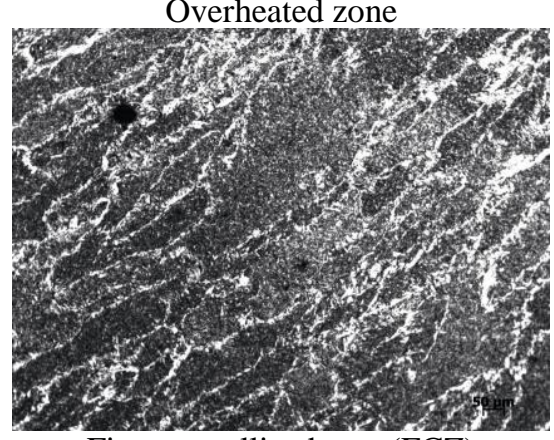

First crystallized zone(FCZ) 


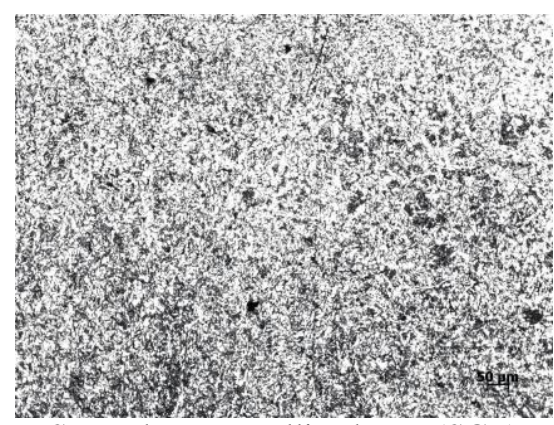

Secondary crystallized zone(SCZ)

Figure 3. Metallographic figures of narrow gap automaric MAG welding joint's different zones

As we can measure from the above fugures, the crystal degree of the base matel is 7-8 grade and its grain size is about 20-40 microns, while the crystal in the INZ is 8-10 grade and 10-20 microns. As we can see, the crystal in the CNZ is extremely fine, whose grain size is less than 10 microns and crystal degree is more than 10 grade. The overheated zone's microstructure is lath martensite and the prior austenite grain boundary is still visible in the figure, on this basis, it can be inferred that the prior austenite's grain size is about 60-100 microns and the crystal degree is 2-4 grade, which is larger than the base metal crystal. There's columnar crystal in the first crystallization zone, whose brachyaxis is about 100-150 microns, macroaxis is about 400-600 microns and the crystal degree is 1-2 grade [8]. While the secondary crystallization zone's crystal size is between base metal's and the completely normalized zone's, which is about 10 microns and its crystal degree is about 10 grade.

\section{THE MECHANICAL PROPERTIES OF WELDING JOINT}

\section{A. Microhardness of different organizations}

Along the line across the weld, measure different organizations' microhardness of the Q345B welding joint by the narrow gap automatic MAG welding in the order of base metal to HAZ, HAZ to weld, weld to HAZ, and HAZ to base metal. Measure 80 equal-distant points in total and the result is shown in Fig . 4.

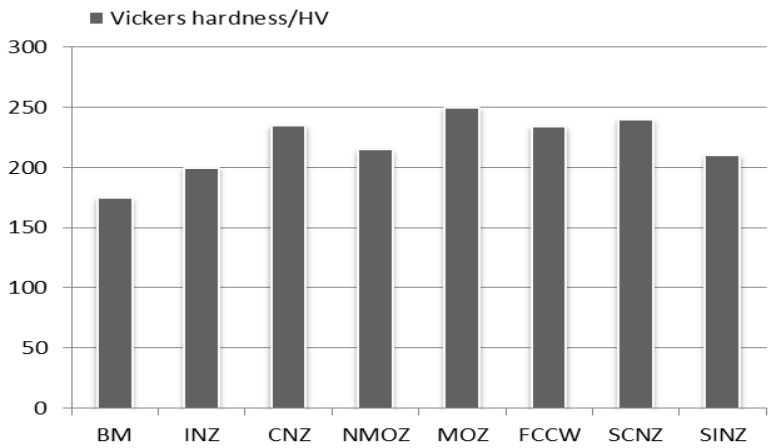

Figure 4.Hardness of the welding joint

\begin{tabular}{|l|l|l|}
\hline \multirow{3}{*}{ NOTE } & NMOZ & Non-martensite in overheated zone \\
\cline { 2 - 3 } & MOZ & Martensite in overheated zone \\
\cline { 2 - 3 } & FCCW & The first columnar crystal in weld \\
\hline
\end{tabular}

The histogram shows that the overheated martensite of average hardness of $250 \mathrm{HV}$ in the first HAZ is the hardest part of the whole joint. Though the columnar crystal is larger, its hardness is 50HV higher than the base metal. The major reason is that the filler metal has more carbon than the base metal, which fills in the weld and makes it harder,besides, the addition of $1.52 \% \mathrm{Mn}$ to the filler metal makes the weld stronger because of alloying effects. The other reason is that the columnar crystal is a mixture of acicular ferrite and fine-grannular carbide. The average hardness of the secondary heated zone is also higher than base metal's for alloying effects. Although there is certain coarsening in the overheated zone, its hardness descends slightly, since the zone is a non-equilibrium microstructure and the non-martensite is a mixture of equiaxial ferrite and precipitates, whose average hardness is $210 \mathrm{HV}$, namely, $40 \mathrm{HV}$ higher than the base metal. It proves that the heat-affected zone especially the overheated zone has a better mechanical property though the welding process used in this paper has lower heat input than traditional MAG welding.

\section{B. $\quad$ Stretching and lateral bending}

Fig .5 shows the fracture of the tensile specimen. The welding joint tensile test shows all fractures happen on the base metal, proving that the welding joint is stronger than base metal. The Q345B steel plate tested is $50 \mathrm{~mm}$ thick and tensile strength reaches 490-620 MPa. The tensile specimen's averge tensile strength is 515 $\mathrm{MPa}$, higher than the lower limit of base metal's tensile strength.

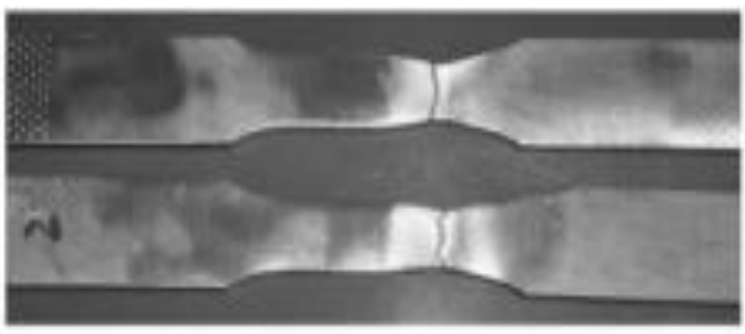

Figure 5.The tensile specimen welded by narrow gap automatic MAG welding

According to the lateral bending test on the upper and lower portions of the welding joint of the indenter, which is $40 \mathrm{~mm}$ in diameter with $70 \mathrm{~mm}$ roller spacing and 180-degree bending angle, only two $0.5 \mathrm{~mm}$ needle like crack points appear on the sample surface, which meets the international standard of weld lateral bending [9].

\section{Impact property}

Do impact test on the base metal, HAZ and weld seam centre respectively at room temperature (20 degrees Centigrade), and the result is shown as TABLE III. 
TABLE III. IMPACT ABSORBING ENERGY OF THE NARROW GAP AUTOMARIC MAG WELDING Q345B JOINT

\begin{tabular}{|c|c|c|c|c|}
\hline \multirow{2}{*}{$\begin{array}{c}\text { Notch } \\
\text { position }\end{array}$} & \multirow{2}{*}{$\begin{array}{c}\text { Test } \\
\text { temperature } \\
\text { (centigrade) }\end{array}$} & \multicolumn{3}{|c|}{ Impact absorbing energy A/Kv (J) } \\
\cline { 3 - 5 } & 20 & $201,205,210$ & 201 & 205.3 \\
\hline $\begin{array}{c}\text { Base } \\
\text { metal }\end{array}$ & 20 & $230,200,256$ & 200 & 228.7 \\
\hline HAZ & 20 & $167,150,150$ & 150 & 155.7 \\
\hline $\begin{array}{c}\text { Weld } \\
\text { seam } \\
\text { centre }\end{array}$ & & & & \\
\hline
\end{tabular}

It shows that the HAZ has the best impact toughness, which proves again that the mechanical property of Q345B welding joint gets improved after the narrow gap automatic MAG welding process. And the reason for weld seam's lower impact absorbing energy is that there is widmanstatten in the columnar crystal grain boundary [10].

\section{CONCLUSiOns}

Through narrow gap automatic MAG welding, the Q345B weld seam forms well, both sides of the groove get welded fully, almost no defects such as blowholes and cracks exist in the weld and its mechanical property meets the international standard.

\section{REFERENCES}

[1] Yongjian Yang, Xuping Zhang, Xiaoqian Qi \& Yuchen Zhao (2012). The microstructure and mechanical properties of welding joint of Q345 steel by MAG welding process analysis.Welding technique, 40(12):pp.6-8.

[2] Xinchao Ma. (2013). Analysis on microstructure of Q345B welding joint. Physical Testing and Chemical Analysis: Physical Fascicule, (11), pp.717-722.

[3] Yurong Song, Minyong Fang, Yulin Cao, Jun Wang \& Chaobo Wei. (2013). The main steel frame making and welding process of tower type furnace. Metal processing: Hot working, (4):pp.59-62

[4] Xiang Yu \& Xiaoliang Wang. (2012). Research on pressure vessel welded by narrow gap MAG welding. Equipment manufacturing technology, (11): pp.123-124.

[5] Hori.K and Kawakara.M. Application of narrow gap process by S.Sawada[J]. Welding Journal, 1985, 9: 18-19.

[6] Fuju Zhang,Weigang Xu,Effect of welding heat input on HAZ character in ultra-fine grain steel welding $[\mathrm{J}]$. China Welding. 2003(02) pp..42-47.

[7] Wang Weibin,Shi Yaowu,Sha Peng,Lei Yongping,Tian Zhiling. Study on the flash butt welding of $400 \mathrm{MPa}$ ultra-fine grain steel[J]. Journal of Materials Engineering and Performance. 2003 (5) pp.56-59.

[8] M. Divya, C.R. Das, S.K. Albert et al.. Influence of welding process on Type IV cracking behavior of P91 steel [J]. Materials Science \& Engineering A, 2014, pp.613-615.

[9] CMES \& CWS. Welding handbook. [M]Beijing: China Machine Press, 2001:pp.121-123.

[10] Zhongqi Cui. Metallography and heat treatment. [M]Beijing: China Machine Press, 1980:223-226. 